\title{
Phenotypic assessment of rice (Oryza sativa L.) genotypes for genetic variability and varietal diversity under direct seeded condition
}

\author{
Anurag Tripathi ${ }^{* 1}$, Sudhir Kumar ${ }^{2}$, Mithilesh Kumar Singh ${ }^{1}$, Arun Kumar ${ }^{1}$ and Mukesh \\ Kumar Karnwal ${ }^{1}$ \\ ${ }^{1}$ Department of Genetics and Plant Breeding, College of Agriculture, Govind Ballabh Pant University of \\ Agriculture and Technology, Pantnagar-263145 (Uttarakhand), INDIA \\ ${ }^{2}$ Division of Molecular Biology and Biotechnology, National Research Centre for Plant Biotechnology IARI, \\ New Delhi-110012, INDIA \\ *Corresponding author. E-mail: Anuragtripathi855@gmail.com
}

Received: January 22, 2016; Revised received: October 24, 2016; Accepted: January 1, 2017

Abstract: The study on variability and diversity of 32 genotypes of rice (Oryza sativa L.) under direct seeded condition revealed significant variability at $5 \%$ level among the genotypes for all the characters. High level of broad sense heritability was observed for days to $50 \%$ flowering $(0.986)$ followed by filled grains $(0.8216)$ and 1000 -grain weight (0.7306). Expected genetic advance was highest for yield per hectare (39.639) and filled grains per panicle (51.39). Genetic divergence analysis using Mahalanobis's $D^{2}$ statistic grouped the genotypes into 7 clusters. Cluster II had maximum number (16) of genotypes. Maximum inter cluster distance was found between cluster IV and VII (984.82). However, intra cluster distance was maximum in cluster III (363.58). Genotypes from diverse clusters viz.NR 89, PAU 3284, ARIZE SWIFT, RY 248, Varadhan, RYC489, MTU 1010 and RYC 674 could be recommended for inclusion in hybridization programme for breeding under aerobic rice condition.

Keywords: Aerobic rice, Genetic divergence, Rice, Varietal diversity

\section{INTRODUCTION}

Genetic variation is the spice of plant breeding programme as it widens the scope of selection. Therefore, estimation of extent and nature of diversity in the germplasm accessions for yield and other economic traits is critical. The exploitable variability is judged through simple measure of variability through $\mathrm{D}^{2}$ statistics. Estimates of heritability and genetic advance help in understanding the nature of gene action affecting the concerned trait (Sravan et al., 2012).

Genetic diversity and the diverse gene pools is lifeline of any breeding programme that provides opportunity for identification of traits that offer substantial scope for improvement through selection if higher level of productivity is to be achieved and sustained. Genetic divergence is an outcome of several factors such as exchange of breeding material, genetic drift, natural variation and artificial selection other than ecological and geographical diversification (Sirohi and Dar, 2009). The greater the diversity among the parents higher is the chances of achieving heterotic progeny and a broad spectrum variability in segregating generations. Thus, assessment of genetic diversity for different traits in the germplasm is essential for the identification of suitable parents in the hybridization programme (Sharma et al., 2008).
In view of the scarce water situation in most of the rice growing areas in Uttarakhand we have taken up this experiment to judge the inter-trait variability and varietal diversity in rice genotypes under direct seeded condition to screen the genotypes that can be used as cultivar or surrogate parent in hybridization programs for moisture stress regime.

\section{MATERIALS AND METHODS}

32 rice genotypes including 1 local check i.e. Pant Dhan 12, were included in present study. The experiment was laid in complete randomized block design (RBD) with three replications. The standard agronomic practices were followed to raise a healthy crop. Observations were recorded on five randomly selected plants for 6 quantitative traits viz. tiller number per plant, days to $50 \%$ flowering, panicle length $(\mathrm{cm})$, number of filled grain per panicle, 1000-grain weight (g) and grain yield/hectare (Kg/ha). Statistical tools like analysis of variance (Panse and Sukhmate, 1967), coefficients of variability (Burton, 1952), heritability (Allard, 1960), genetic advance (Allard, 1960) and $\mathrm{D}^{2}$ statistics (Murthy and Arunachalam, 1967) were used for analysis.

\section{RESULTS AND DISCUSSION}

Variability: Analysis of variance for 6 yields and its 
Table 1. Analysis of variance for different quantitative traits among rice genotype under aerobic condition.

\begin{tabular}{llllllll}
\hline \multirow{2}{*}{$\begin{array}{l}\text { Source } \\
\text { variation }\end{array}$} & \multirow{2}{*}{$\begin{array}{l}\text { Degree } \\
\text { freedom }\end{array}$} & $\begin{array}{c}\text { Days to 50\% } \\
\text { flowering }\end{array}$ & $\begin{array}{l}\text { Panicle } \\
\text { length }\end{array}$ & $\begin{array}{c}\text { Tiller no } \\
\text { per plant }\end{array}$ & $\begin{array}{c}\text { Filled grain } \\
\text { per panicle }\end{array}$ & $\begin{array}{c}\mathbf{1 0 0 0} \text { grain } \\
\text { weight }\end{array}$ & $\begin{array}{c}\text { Yield/ ha } \\
\text { (kg/ha) }\end{array}$ \\
\hline Replication & 2.0 & 0.562 & 1.15 & 18.04 & 61.81 & $1.771^{* *}$ & 24512.00 \\
Treatment & 31.0 & $80.96 * *$ & $3.46^{*}$ & $2.06 * *$ & $2439.5^{* *}$ & $45.96^{* *}$ & $413214.3^{* *}$ \\
error & 62.0 & 0.422 & 2.05 & 0.987 & 165.09 & 5.023 & 136942.8 \\
\hline
\end{tabular}

*significant @ p=0.05, **significant @ p=0.05

Table 2. Estimates of variability parameters for different quantitative traits among rice genotypes under aerobic condition.

\begin{tabular}{lcccccccc}
\hline Characters & Range & GM & SEm \pm & $\mathbf{P C V}$ & $\mathbf{G C V}$ & $\mathbf{h}^{\mathbf{2}}$ & $\mathbf{G}_{\mathbf{A}}$ & $\mathbf{G}_{\mathbf{A}}$ in \% of mean \\
\hline Day To 50\% Flowering & $72-93$ & 79.864 & 0.375 & 6.545 & 6.499 & 0.986 & 10.622 & 13.30 \\
Panicle length of main axis & $24.13-28.47$ & 26.864 & 0.826 & 6.24 & 1.25 & 0.404 & 0.139 & 0.51 \\
Tiller / Plant & $6-11$ & 8.416 & 0.573 & 15.93 & 7.25 & 0.207 & 0.583 & 6.93 \\
Filled grain per panicle & $108-210$ & 145.95 & 7.41 & 20.81 & 18.86 & 0.821 & 51.39 & 35.21 \\
1000 grain weight & $10.1-28.6$ & 21.583 & 1.29 & 20.01 & 17.11 & 0.730 & 6.50 & 30.12 \\
Grain yield /ha & $3278-4694.33$ & 3856.083 & 213.65 & 12.41 & 7.86 & 0.402 & 39.639 & 10.27 \\
\hline
\end{tabular}

contributing traits in rice indicated that, mean square differences among 32 genotypes for all the characters studied are highly significantat $5 \%$ level of probability (Table1). Thus, there is sufficient scope for further improvement in these characters under direct seeded environment.

Genetic variability: Estimates of variability parameters for different quantitative traits among genotypes in rice are presented in Table 2.Number of tillers per plant varied from 6 to 11 with coefficient of variation CV 11.80. Genotypes MTU 1010, NR89 and RYC 248 were superior genotypes with 11, 10 and 10 tillers/ plant respectively. Days to $50 \%$ flowering varied from 72 to 93 with CV 2.81. Genotypes Wardhan, PD12, and NP9161 were superior that flowered in 72, 73 and 74 days respectively. Panicle length ranged from $24.13 \mathrm{~cm}$ (Konark) to $28.47 \mathrm{~cm}$ (RYC248) with CV 5.33. Genotypes RYC248, Tehalka and NP9161 are the best genotypes that have panicle length of $28.47,28.00$ and $27.87 \mathrm{~cm}$ respectively. Number of filled grains per panicle ranged from 108 to 210 with CV 8.80. Tehlka, RXML01 and Rajendra kasturi having 210, 205 and 202 filled grain per panicle respectively are the superior genotypes. 1000-grain weight ranged from 10.0 to 28.16 grams with $\mathrm{CV} 10.38$. The genotype DRH834 produced highest 1000 grain weight (28.16 g) followed by NPH24 (27.67 g). Total yields per hectare $(\mathrm{Kg} / \mathrm{ha})$ ranged from $3278 \mathrm{Kg}$ to 4694.33 Kg with CV 9.59. The genotype RYC674 (4694.33Kg) followed by Sabour Surhit $(4351.00 \mathrm{Kg})$ and Arize Swift $(4340.00 \mathrm{Kg})$ were highest yielding genotypes.

PCV and GCV: The moderate to high value for PCV and GCV (Table 2) was recorded for total number of filled grain per panicle $(20.81,18.86)$ and test weight (20.01, 17.11). However, narrow gap between these values indicate that these traits are least influenced by environment. Low value for PCV and GCV were recorded for days to $50 \%$ flowering $(6.54,6.499)$ and panicle. Bhadru et al. (2012) reported high PCV and GCV for number of grains per panicle, and grain yield per plant in rice.A relatively large gap between PCV and GCV for these two traits is indicative of environmental influence on trait expression. The similar results in transplanted rice were reported by Panwar et al. (2005). Similar finding of PCV and GCV have also been reported in Rice for days to $50 \%$ flowering and Grain yield per plant by Singh et al. (2006).Similar finding of PCV and GCV have been reported for total grains per panicle, grain yield per plant and number of effective tillers per plant, while the lowest in days to maturity and days to 50 per cent flowering in rice by Khare et al. (2014).

Heritability and genetic advance: Very high level of broad sense heritability was observed for days to $50 \%$ flowering (0.9867) followed by filled grain per panicle $(0.821), 1000$ grain weight $(0.730)$ and grain yield /ha $(0.402)$. These results are in accordance with reports of Nayak et al. (2002) in scented Rice under Rainfed condition. This serves as an index of transmissibility of traits from parents to their offspring. But character exhibiting high heritability may not necessarily give high genetic advance (Gandhi et al., 1964) because of involvement of non-additive gene action. Thus, selection for the characters should be based on high heritability as well as high genetic advance (Johnson et al., 1955). The genetic advance was highest for grain yield/ha (39.639) followed by filled grain per panicle (51.39), while low genetic advance was observed for panicle length (0.139) (Table 2). Similar results were also reported by Pratap et al. (2012) and Gangashetty et al. (2013) in rice. Heritability coupled with expected genetic advance for a trait will help us in deciding the scope of improvement of that particular trait through selection (Johnson et al., 1955).

Diversity: Genetic diversity and the diverse gene pool are the basis of plant breeding. Genetic diversity is essential if higher level of productivity is to be achieved because it providing genetic building blocks for further improvement. Hence, genetic diversity is necessary for progress to be made in plant breeding as well as during selection of parental genotypes for crossing programme. Based on the $\mathrm{D}^{2}$ values, the constellation on genotype into clusters was done as sug- 
Table 3. Distribution of different rice genotypes into clusters based on $\mathrm{D}^{2}$ statistics.

\begin{tabular}{llc}
\hline Cluster & Name of genotypes & Number of genotypes \\
\hline I & Tehlka & 1 \\
& US350,NP9161,NPH24,US375,RXML & 16 \\
II & (01),DRH834,SVH027,Lalat,konark,RajendraKasturi, & 5 \\
& RYC230,RYC232,RYC238,RYC237,GGV0501,Pant Dhan12. & 4 \\
III & Dhaanya080544,NR89,PAU3284,ARIZE SWIFT,RYC248 & 4 \\
IV & PD12,Varadhan,RYC489,MTU1010 & 1 \\
V & NPH5,PAU3285,RYC667,RAJENDRA SUWASINI & 1 \\
VI & SABOUR SURHIT & \\
VII & RYC674 & \\
\hline
\end{tabular}

Table 4. Average inter cluster (above diagonal) and intra cluster (diagonal) $\mathrm{D}^{2}$ values in rice.

\begin{tabular}{|c|c|c|c|c|c|c|c|}
\hline Cluster & I & II & III & IV & $\mathbf{V}$ & VI & VII \\
\hline I & $\mathbf{0}$ & 238.359 & 135.25 & 258.63 & 133.14 & 424.40 & 760.10 \\
\hline II & & 273.60 & 256.70 & 39.80 & 257.82 & 625.10 & 964.04 \\
\hline III & & & 363.58 & 276.42 & 30.55 & 372.45 & 709.63 \\
\hline IV & & & & 312.01 & 280.16 & 643.63 & 984.82 \\
\hline $\mathbf{V}$ & & & & & 164.58 & 370.87 & 707.18 \\
\hline VI & & & & & & 0 & 348.45 \\
\hline VII & & & & & & & 0 \\
\hline
\end{tabular}

gested by Rao (1952). All the 32 genotype were grouped into seven clusters.(Table 3). Clustering pattern of genotypes showed lack of any relationship between geographic origin and genetic diversity reported by Chandra et al. (2007) and Bhanumathi et al. (2010). Cluster I(Tehlka), VI(SabourSurhit) and VII (RYC674) contained only one genotype each. Cluster II comprises of sixteen genotype (US350, NP 9161,NPH 24,US 375,RXML 01,DRH 834,SVH027, Lalat, konark, Rajendra kasturi, RYC 230,RYC 232,RYC 238,RYC 237,GGV0501,Pant dhan 12). The Cluster III having five genotypes (Dhaanya 080544, NR89, PAU 3284, ARIZE SWIFT, and RYC 248). Cluster IV comprises of four genotype (PD12, Varadhan, RYC489, MTU1010). Cluster V contains four genotypes (NPH5, PAU3285, RYC667, and RajendraSuwasini). While cluster VI contains only one genotype (SABOUR SURHIT) and cluster VII contain one genotypes (RYC 674). The results indicated that, the diversity reported among the genotype is due to both geographical diversification and genotypic differences which played a major role in the clustering along with the similarity and differences in their adaptation, selection criteria, selection pressure and environmental condition (Nayak et al., 2004 and Bose and Pradhan, 2005).

Intra cluster genetic distance: Intra cluster average $\mathrm{D}^{2}$ values ranged from 0.0 to 363.59 it was maximum in cluster III with five genotypes (Dhaanya 080544,NR89,PAU 3284,ARIZE SWIFT, RYC 248) followed by cluster IV with four genotypes (PD12, Varadhan,RYC489, MTU1010). According to findings, selection of parents should be done from these two cluster III and cluster IV having wider inter-cluster distance to get more variability and high heterosis effect for yield and its contributing traits. The maxi- mum intra cluster distance was observed in cluster III. Hence under directed seeded condition selection within these cluster may be exercised based on the highest mean for the desirable trait, which could be made use in further improvement through inter varietals hybridization as well as in recombination breeding. Similar findings have been reported by De and Rao (1987), Pradhan and Roy (1990), Mishra et al. (2003) and Chaturvedi and Maurya (2005) in transplanted rice.

The inter cluster genetic distance: The inter cluster average $\mathrm{D}^{2}$ values was maximum (984.856) between cluster VII with one genotypes, (RYC674) and cluster III with five genotype (Dhaanya080544, NR89, PAU3284, ARIZRSWIFT, RYC248). Therefore choice of divergent parent can be made from these two diversified clusters for hybridization purpose to get high heterotic effects for grain yield and its concerned traits under aerobic environment. The results are close confirmation with the findings of Joshi et al. (2008) clustered eighteen rice varieties on the basis of sixteen quantitative characters using numerical taxonomic approach were grouped into nine different clusters revealing sufficient amount of variability among the varieties.

\section{Conclusion}

Ample variability among the genotypes for all the characters studied in Rice under direct seeded condition indicated scope for improvement in seed yield and its related traits. A high level of broad sense heritability for days to $50 \%$ flowering filled grains and 1000 grain weight along with high expected genetic advance for yield per hectare and filled grains per panicle can be viewed in the light of scope of genetic progress of these traits under selection cycle. The pattern of clustering proved that geographical diversity 
need not necessarily be related to genetic diversity and genotypes. Present investigation revealed that, three cluster showed maximum intra and inter cluster D2 values having the diversified genotype including NR 89, PAU 3284, ARIZE SWIFT, RY 248 (in Cluster III), Varadhan, RYC489, MTU 1010 (in cluster IV) and RYC 674 (in cluster VII) should be recommended for inclusion in inter varietal hybridization programme as well as in recombination breeding to improve the yield and its related traits under aerobic rice cultivation.

\section{REFERENCES}

Allard, R.W. (1960). Principles of Plant Breeding. John Wiley and Sons Inc. New York, pp. 485.

Banumathi, S., Manimaran, R., Sheeba, A., Manivannan, N., Ramya, B., Kumar, D. and Ramasubramanian, G. V. (2010). Genetic diversity analysis of rice germplasm lines for yield attributing traits. Electronic Journal of Plant Breeding, 1(4): 500-504

Bhadru, D., Rao, Tirumala, V., Mohan, Chandra, Y. and Bharathi, D. (2012). Genetic variability and diversity studies in yield and its component traits in rice Oryzasativa L.). SABRAO Journal of Breeding and Genetics, 44(1): 129-137

Bose, L. K. and Pradhan, S. K. (2005). Genetic divergence in deep water rice genotype. J. Central European Agri., 6 (4): $635-640$

Burton, G.W. (1952). Quantitative inheritance in grasses. Proc. Sixth Grassland Congress, 1: 277-283

Chandra, B. S., Reddy T. D. and Ansari, N. A. (2007). Genetic divergence in rice (Oryza sativaL.). Research on Crops, 8(3):600-603

Chaturvedi, H.P. and Maurya, D.M. (2005). Genetic divergence analysis in rice (Oryza sativa L.). Advances in Plant Sciences, 18(1):349-353

De, R.N. and Rao. A.V.S. (1987). Genetic divergence in rice under low land situation. Crop lmprov., 14:128-131

Gandhi, S. M., Sanghli, A.K., Nathawat K.S. and Bhatnagar, M.P. (1964). Genotypic variability and correlation coefficient relating to grain yield and few other quantitative characters in Indian wheat. Indian J. Genet., 24:1-8

Gangashetty, P., Salimath, P. and Hanamaratti, N. (2013). Genetic variability studies in genetically diverse nonbasmati local Aromatic genotypes of rice (OryzasativaL). Rice Genomics and Genetics, 4(2):4-8

Johnson, H.W., Robinson, H.F. and Comstock, R.E. (1955). Estimates of genetic and environmental variability in soybean. Agron. J., 47: 314-318
Joshi, M.A., Singh, P., Sarao, N.K., Sharma, R.C. and Bharaj, T. S. (2008). Genetic diversity among rice varieties cultivated in Panjab. Oryza, 45(4): 277-279

Khare, R., Singh, A.K., Eram, S. and Singh, P.K. (2014). Genetic Variability, Association and Diversity Analysis in upland rice (Oryzasativa L) SAARC J. Agri., 12(2): 40-51

Mishra, L.K., Sarawgi, A.K. and Mishra, R.K. (2003). Genetic diversity for morphological and quality traits in rice (Oryza sativa L.). Advances in Plant Sciences, 16 (1):287-293

Murthy, B. R. and Arunachalum, V. (1967). Computer programmes for some problems in biometrical genetics. Use of Mahalanobis $\mathrm{D}^{2}$ in classification problem. Indian J. Genet. Pl. Breed., 27: 60-69

Nayak, A.R., Chaudhury, D. and Reddy, J.N. (2002). Genetic variability, heritability and genetic advance in scented rice. Indian Agric., 46 (12): 45-47

Nayak, A. R., Chaudhury, D. and Reddy, J. N. (2004). Genetic divergence in scented rice. Oryza, 41: 79-82

Panse, V.G. and Sukhatme, P.V. (1967). Statistical methods for agricultural workers. Indian Council of Agricultural Research, New Delhi.

Panwar, L.L. (2005). Genetic variability, heritability and genetic advance for panicle characters in transplanted rice (Oryzasativa L.). Agric. Res. Stat., 6(3): 505-508.

Pradhan, A.K. and Roy, A. (1990). Genetic divergence in rice. Oryza, 27(4): 415-418

Pratap, N., Singh, P.K., Shekhar, R., Soni, S.K. and Mall, A.K. (2012). Genetic variability, character association and diversity analyses for economic traits in rice (oryzasativa L.). SAARC Journal of Agriculture, 10(2): 83-94

Rao, C.R. (1952). Advance statistical methods in biometrical research. Ed. II. New York . John Willey \& Sons

Sharma, R.K., Gupta, P., Sharma, V., Sood, A., Mohapatra, T. and Ahuja, P.S. (2008). Evaluation of rice and sugarcane SSR markers for phylogenetic and genetic diversity analyses in bamboo. Genome, 51(2): 91-103.

Singh, S.P., Singhara, G.S., Parray, G.A. and Bhat, G.N. (2006). Genetic variability and character association studies in rice (Oryzasativa L.). Agric. Science Digest, 26 (3): 212-214

Sirohi, S. P. S. and Dar, A. N. (2009). Genetic divergence in soybean (Glycine max L. Merrill). SKUAST Journal of Research, 11(2): 200-203

Sravan, T., Rangare, N. R., Suresh, B. G. and Ramesh kumar, S. (2012). Genetic variability and character association in rainfed upland rice (Oryza sativa L.). Journal of Rice Research, 5(1\&2): 24-29 